\title{
Medication for Hypercholesterolemia and the Risk of Nonfatal Acute Myocardial Infarction A Case-Control Study in Japan
}

\author{
The Fukuoka Heart Study Group*
}

\begin{abstract}
While lowering the blood cholesterol level has been shown to decrease the risk of coronary heart disease (CHD) in Western countries, little is known about the relationship between lipid-lowering drugs and CHD risk in Japan. A case-control study of nonfatal acute myocardial infarction (AMI) was conducted in Japan. A total of 658 cases aged 40-79 years and 1,274 community controls matched to each case by sex, year of birth, and residence were compared for their use of lipid-lowering drugs and level of serum total cholesterol. The study used 2 definitions of hypercholesterolemia: (i) either serum total cholesterol $\geq 6.21 \mathrm{mmol} / \mathrm{L}(240 \mathrm{mg} / \mathrm{dl})$ or current use of hypolipidemic drugs; and (ii) either serum total cholesterol of $\geq 5.69 \mathrm{mmol} / \mathrm{L}(220 \mathrm{mg} / \mathrm{dl})$ or current use of hypolipidemic drugs. Unconditional logistic regression analysis was used to adjust for hypertension, angina pectoris, diabetes mellitus, smoking, alcohol use, and physical activity as well as for sex and age. As compared with nonhypercholesterolemic subjects, those with untreated hypercholesterolemia had a significantly increased risk of AMI whereas no increase in the risk was observed for treated hypercholesterolemia. In the group with hypercholesterolemia, regardless of the definition, the adjusted odds ratios decreased progressively when the achieved cholesterol levels were lower. (Circ J 2002; 66: 463-468)
\end{abstract}

Key Words: Hypercholesterolemia; Medication; Myocardial infarction

$\mathbf{E}$ levated levels of serum total or low-density lipoprotein cholesterol have been related to increased risk of coronary heart disease (CHD) in many prospective studies in Western countries,-4 and it has been consistently shown in randomized controlled trials that lowering blood cholesterol reduces both the incidence and recurrence of CHD events. ${ }^{5-13}$ A positive association between serum total cholesterol and CHD has been observed in Asian populations with relatively low levels of serum total cholesterol and at low risk of $\mathrm{CHD}^{14,15}$ but it is unclear whether the beneficial effect of lowering blood cholesterol observed in Western populations is directly applicable to Japanese subjects with hypercholesterolemia. A small clinical trial in Japan showed that the use of pravastatin resulted in regression of coronary atherosclerosis ${ }^{16}$ but a randomized controlled trial regarding the prevention of CHD events by medication for hypercholesterolemia has never been successfully completed ${ }^{17}$ We designed a case-control study, the Fukuoka Heart Study ${ }^{18,19}$ to investigate the relationship between medication for hypercholesterolemia and the risk of nonfatal acute myocardial infarction (AMI) in Japanese men and women.

\section{Methods}

The study was designed and implemented in accordance with the Declaration of Helsinki adopted by the 18th World

(Received October 18, 2001; revised manuscript received February 12, 2002; accepted February 15, 2002)

*Members of the Fukuoka Heart Study Group are listed in Appendix. Mailing address: Suminori Kono, MD, Department of Preventive Medicine, Faculty of Medical Sciences, Kyushu Univeristy, 3-1-1 Maidashi, Higashi-ku, Fukuoka 812-8582, Japan. E-mail: skono@ phealth.med.kyushu-u.ac.jp
Medical Assembly; observational studies were not the subject of review by the institutional ethical committee at the time of the survey. Study subjects were patients with a first episode of AMI and matched community controls. Written informed consent was given by all participating individuals.

\section{Cases and Controls}

Eligible cases were patients aged 40-79 years who were admitted to hospital for a first AMI during September 1996 to September 1998 and who recovered well enough to be interviewed within 1 month after the onset of AMI. The eligible cases were originally restricted to residents of Fukuoka City, but were extended to those of 21 adjacent municipalities in June 1997. Thirteen hospitals were selected to cover the patients in Fukuoka City when the study began, and 9 other hospitals outside Fukuoka City were subsequently included. These collaborating hospitals were staffed with one or more expert cardiologists and were equipped with facilities for treating AMI.

Research nurses visited each hospital weekly, checked all admissions with a diagnosis of AMI or suspected AMI, and asked eligible patients to participate in the study. Collaborator cardiologists were in charge of the diagnosis of AMI, which was made on the basis of electrocardiographic findings, ischemic cardiac pain lasting at least 30 min, and enzyme changes in accordance with the criteria used in the Lipid Research Clinics Coronary Primary Prevention Trial.$^{20}$ Of 756 eligible patients, a total of 660 (87\%) participated in the study. Reasons for non-participation were impaired ability to communicate $(n=9)$, discharge before interview $(n=65)$, and refusal $(n=22)$. Two cases were excluded in the analysis because their serum total cholesterol values were not available. 
One or 2 controls matched to each case for sex, year of birth (within 2 years), and proximity in residence were surveyed. A total of 2,613 individuals selected from the resident registers were approached by mail between September 1996 and March 1999, with 2 reminders sent to those who did not respond. Contact by telephone was attempted last. The outcome of recruiting controls was: undelivered mail 53, deceased 22, nonresident 26, prior history of MI 79, refusal 889, no registered telephone number 267 , participation 1,277 . The net participation rate was estimated to be $52 \%(1,277 / 2,433)$. One case did not have a control and only 1 control was surveyed for each of 41 cases. Serum total cholesterol values were not available for 3 controls. Thus, 658 cases and 1,274 controls comprised the present study group.

\section{Interview Survey}

A questionnaire was used to ascertain demographic characteristics, lifestyle factors such as smoking, alcohol use, and physical activity, and medical history of hyperlipidemia, hypertension, angina pectoris, and diabetes mellitus. The reference period for AMI cases was before the onset of symptoms and before the time of interview for the controls. Alcohol intake was estimated from reported frequencies and amounts consumed per occasion of 4 different alcoholic beverages (shochu, sake, beer, and whiskey/brandy) on average in the past year. Questions on leisure-time physical activity asked about the number of days on which subjects had exercised per week on weekdays and per month on weekends or holidays on average over the past year, the type of regular activity, and the average amount of time spent in each activity. Physical activity was classified into 4 levels of intensity in terms of metabolic equivalents $(\mathrm{METs})^{21}$ The MET score (light $=2$, moderate $=4$, $\operatorname{hard}=6$, and very hard $=8$ ) was multiplied by the number of hours per week engaged in each activity to yield the MET-hours per week as an index of leisure-time physical activity.

While they were in hospital, the patients were given the questionnaire and interviewed by the research nurses. The questionnaire was mailed to control subjects and then the research nurses and members of the working group (physicians and a public health nurse) interviewed them at their clinic if they were under medical supervision, at work, at home or at Kyushu University.

\section{Clinical Data}

For the AMI cases, the research nurses investigated current medication prior to the onset of AMI and the initial serum concentration of total cholesterol at the time of admission. When a blood sample had not been taken within $24 \mathrm{~h}$ of the onset of AMI, the primary physician was asked about serum lipid measurements immediately after, or alternatively before, the onset of AMI. According to the time of the cholesterol measurement, 430 cases were measured within $24 \mathrm{~h}$ of onset, 11 were determined between 25 and $48 \mathrm{~h}, 144$ were measured more than $48 \mathrm{~h}$ after and 73 had had their cholesterol measured within 1 year prior to onset.

For the controls, a nonfasting, venous blood sample was taken for the determination of serum lipids in the Clinical Laboratory of the Fukuoka City Medical Association. If subjects were reluctant to give a blood sample, information about serum total cholesterol measurements within the 6 months prior to the interview were obtained from the subjects or their physicians. Current medication was listed from the medical records.

Hypertension and angina pectoris were defined as present if subjects had ever been prescribed medication for these conditions. Subjects under dietary or pharmacological treatment for diabetes mellitus were classified as having the disease. We used 2 definitions of hypercholesterolemia; the first definition was either serum total cholesterol $\geq 6.21$ $\mathrm{mmol} / \mathrm{L}(240 \mathrm{mg} / \mathrm{dl})$ or current use of hypolipidemic drugs (high total cholesterol); and the second was either serum total cholesterol $\geq 5.69 \mathrm{mmol} / \mathrm{L}(220 \mathrm{mg} / \mathrm{dl})$ or current use of hypolipidemic drugs. The first definition was used by the National Cholesterol Education Program in the United States, 22 and the second was the definition used by the Japanese Atherosclerosis Society ${ }^{23}$ The hypolipidemic drugs and serum total cholesterol concentrations prior beginning the drug therapy were ascertained from the medical records at the time of interview or, with the patient's permission, by asking the physicians prescribing the drugs if the patients permitted such an inquiry.

\section{Statistical Analysis}

The relation between medication for hypercholesterolemia and the risk of AMI was analyzed by unconditional logistic regression analysis with adjustment for sex, 5-year age class, hypertension, angina pectoris, diabetes mellitus, smoking, alcohol use, leisure-time physical activity, and family history of MI. Individual matching was disregarded in order to include as many subjects as possible in the analysis. Individuals were classified into 4 groups in terms of smoking (never, former, and current smokers consuming $<20$ or $\geq 20$ cigarettes per day), alcohol use (never, former, and current drinkers consuming $<50$ or $\geq 50 \mathrm{ml}$ of alcohol per day), and leisure-time physical activity (0, 1-9, 10-19, and $\geq 20$ MET-hours). If individuals had missing data (use of hypolipidemic drugs $(n=1)$, hypertension $(n=3)$, angina pectoris $(n=5)$, diabetes mellitus $(n=2)$, family history $(n=49)$, and physical activity $(n=5))$, they were classified as not having that particular factor. Indicator variables were created for these covariates and included as independent variables in logistic regression models. Odds ratio (OR) and $95 \%$ confidence interval (CI) were obtained from the logistic regression coefficient and its standard error estimated for a corresponding indicator variable.

Distributions of the covariates according to the status of hypercholesterolemia were examined by using age-adjusted means or age-adjusted proportions; the former were obtained by analysis of covariance, and the latter by the direct method using the whole subjects stratified by age class as the standard population. Statistical testing for the difference in age-adjusted proportions was done by the CochranMantel-Haenszel general test. Statistical significance was declared if a 2-sided $\mathrm{p}$ value was less than 0.05 or if the $95 \%$ CI did not include unity. All computations were done with the SAS version 6.12 (SAS Institute, Inc, Cary, NC, USA) at the Kyushu University Computer Center.

\section{Results}

The mean age of the male cases and controls was 62.1 and 62.5 years, respectively, and the mean age of both the female cases and controls was 67.5 years. A total of 166 (25\%) cases and $239(19 \%)$ controls had a serum total cholesterol $\geq 6.21 \mathrm{mmol} / \mathrm{L}(240 \mathrm{mg} / \mathrm{dl})$ and/or currently used hypolipidemic drugs. Less than half were under medication: 66 cases and 104 controls. When the cutoff point of 
Table 1 Distribution of Covariates According to Hypercholesterolemia in the Control Subjects*

\begin{tabular}{|c|c|c|c|c|}
\hline \multirow{2}{*}{ Factor } & \multirow{2}{*}{$\begin{array}{c}\text { Nonhyper- } \\
\text { cholesterolemia }\end{array}$} & \multicolumn{2}{|c|}{ Hypercholesterolemia ${ }^{\dagger}$} & \multirow{2}{*}{$p$ value $e^{\frac{1}{x}}$} \\
\hline & & Treated & Untreated & \\
\hline \multicolumn{5}{|l|}{ Males } \\
\hline No. & 802 & 57 & 71 & \\
\hline Mean age (years) & 62.6 & 65.4 & 59.5 & 0.002 \\
\hline Serum total cholesterol $\$$ & $4.85(188)$ & $5.36(207)$ & $6.67(258)$ & $<0.001$ \\
\hline Hypertension & 21.5 & 47.8 & 16.8 & 0.001 \\
\hline Angina pectoris & 3.9 & 9.5 & 2.2 & 0.29 \\
\hline Diabetes mellitus & 9.1 & 14.6 & 8.1 & 0.49 \\
\hline Current smoking & 44.9 & 39.6 & 35.9 & 0.17 \\
\hline Alcohol use, $1+$ times weekly & 66.4 & 57.8 & 64.3 & 0.82 \\
\hline MET-hours, $20+$ weekly & 15.0 & 11.6 & 22.0 & 0.19 \\
\hline Family history & 8.6 & 9.9 & 10.2 & 0.79 \\
\hline \multicolumn{5}{|l|}{ Females } \\
\hline No. & 233 & 47 & 64 & \\
\hline Mean age (years) & 67.3 & 70.4 & 66.4 & 0.04 \\
\hline Serum total cholesterol ${ }^{\S}$ & $5.14(199)$ & $5.67(219)$ & $6.64(257)$ & $<0.001$ \\
\hline Hypertension & 28.7 & 49.7 & 16.8 & 0.001 \\
\hline Angina pectoris & 5.9 & 5.2 & 1.3 & 0.49 \\
\hline Diabetes mellitus & 6.1 & 11.0 & 5.4 & 0.65 \\
\hline Current smoking & 9.9 & 7.2 & 9.4 & 0.93 \\
\hline Alcohol use, $1+$ times weekly & 21.7 & 15.2 & 21.9 & 0.89 \\
\hline MET-hours, $20+$ weekly & 11.1 & 7.7 & 10.4 & 0.80 \\
\hline Family history & 6.1 & 6.1 & 12.4 & 0.10 \\
\hline
\end{tabular}

*Data are age-adjusted percentage unless otherwise specified; ${ }^{\dagger}$ serum total cholesterol $6.21 \mathrm{mmol} / \mathrm{L}(240 \mathrm{mg} / \mathrm{dl})$ or greater and/or

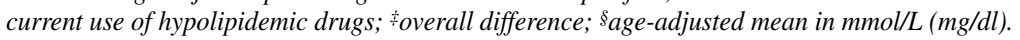

Table 2 Adjusted Odds Ratio (OR) and 95\% Confidence Intervals (CI) of Acute Myocardial Infarction According to Hypercholesterolemia*

\begin{tabular}{|c|c|c|c|}
\hline Definition of hypercholesterolemia & No. cases & No. controls & OR $(95 \% C I)$ \\
\hline \multicolumn{4}{|c|}{$\geq 6.21 \mathrm{mmol} / \mathrm{L}(240 \mathrm{mg} / \mathrm{dl})$ and/or drug use } \\
\hline Non-hypercholesterolemia & 492 & 1,035 & 1.00 \\
\hline Treated hypercholesterolemia & 66 & 104 & $1.01(0.70-1.45)$ \\
\hline Untreated hypercholesterolemia & 100 & 135 & $1.79(1.31-2.44)$ \\
\hline \multicolumn{4}{|c|}{$\geq 5.69 \mathrm{mmol} / \mathrm{L}(220 \mathrm{mg} / \mathrm{dl})$ and/or drug use } \\
\hline Non-hypercholesterolemia & 398 & 873 & 1.00 \\
\hline Treated hypercholesterolemia & 66 & 104 & $1.07(0.74-1.55)$ \\
\hline Untreated hypercholesterolemia & 194 & 297 & $1.64(1.29-2.08)$ \\
\hline
\end{tabular}

*Adjusted for sex, age, hypertension, angina pectoris, diabetes mellitus, smoking, alcohol use, and recreational exercise.

Table 3 Adjusted Odds Ratio (OR) and 95\% Confidence Intervals (CI) of Acute Myocardial Infarction According to the Achieved Level of Serum Total Cholesterol (TC) of the Hypercholesterolemic Subjects*

\begin{tabular}{|c|c|c|c|}
\hline Achieved level of serum TC & No. cases & No. controls & OR $(95 \% C I)$ \\
\hline \multicolumn{4}{|l|}{$\geq 6.21 \mathrm{mmol} / \mathrm{L}(240 \mathrm{mg} / \mathrm{dl})$ and/or drug use } \\
\hline No drugs & 100 & 135 & 1.00 \\
\hline$\geq 6.21 \mathrm{mmol} / \mathrm{L}(240 \mathrm{mg} / \mathrm{dl})$ & 17 & 23 & $0.67(0.30-1.51)$ \\
\hline$<6.21 \mathrm{mmol} / \mathrm{L}(240 \mathrm{mg} / \mathrm{dl})$ & 49 & 81 & $0.47(0.27-0.83)$ \\
\hline \multicolumn{4}{|l|}{$\geq 5.69 \mathrm{mmol} / \mathrm{L}(220 \mathrm{mg} / \mathrm{dl})$ and/or drug use } \\
\hline No drugs & 194 & 297 & 1.00 \\
\hline$\geq 6.21 \mathrm{mmol} / \mathrm{L}(240 \mathrm{mg} / \mathrm{dl})$ & 17 & 23 & $0.84(0.38-1.85)$ \\
\hline $5.69-6.20 \mathrm{mmol} / \mathrm{L}(220-239 \mathrm{mg} / \mathrm{dl})$ & 13 & 21 & $0.78(0.34-1.78)$ \\
\hline$<5.69 \mathrm{mmol} / \mathrm{L}(220 \mathrm{mg} / \mathrm{dl})$ & 36 & 60 & $0.47(0.29-0.80)$ \\
\hline
\end{tabular}

*Adjusted for sex, age, hypertension, angina pectoris, diabetes mellitus, smoking, alcohol use, and recreational exercise.

$5.69 \mathrm{mmol} / \mathrm{L}(220 \mathrm{mg} / \mathrm{dl})$ was used, hypercholesterolemia was present in $260(40 \%)$ cases and $401(31 \%)$ controls. Cases using statins, non-statin drugs, and unknown types of drug numbered 42,7 , and 17 , respectively, and the corresponding numbers of controls were 79,20 , and 5 .

Table 1 shows the distribution of coronary risk factors among the controls with regard to hypercholesterolemia based on the cutoff of $6.21 \mathrm{mmol} / \mathrm{L}(240 \mathrm{mg} / \mathrm{dl})$. In both men and women, hypercholesterolemic subjects under medication were older than those without hypercholesterolemia and those with untreated hypercholesterolemia. Individuals on hypolipidemic drugs had much lower concentrations of serum total cholesterol than those with untreated hypercholesterolemia, but slightly higher values than those without hypercholesterolemia. Hypertension was more prevalent in the group with treated hypercholesterolemia than in the groups of nonhypercholesterolemia and untreated hypercholesterolemia. Diabetes mellitus in 
Table 4 Serum Total Cholesterol (TC) Level Prior to Medication and Current Level According to Achieved Level Categories Among the Hypercholesterolemic Subjects*

\begin{tabular}{|c|c|c|c|c|}
\hline \multirow{2}{*}{ Achieved level of TC } & \multicolumn{2}{|c|}{ Level prior to medication } & \multicolumn{2}{|c|}{ Current level } \\
\hline & No. ${ }^{\dagger}$ & Adjusted mean & No. ${ }^{\dagger}$ & Adjusted mean \\
\hline \multicolumn{5}{|l|}{$\geq 6.21 \mathrm{mmol} / \mathrm{L}(240 \mathrm{mg} / \mathrm{dl})$ and/or drug use } \\
\hline No drugs & 235 & $6.81(263)$ & 235 & $6.81(263)$ \\
\hline$\geq 6.21 \mathrm{mmol} / \mathrm{L}(240 \mathrm{mg} / \mathrm{dl})$ & 25 & $7.07(273)$ & 40 & $6.70(259)$ \\
\hline$<6.21 \mathrm{mmol} / \mathrm{L}(240 \mathrm{mg} / \mathrm{dl})$ & 76 & $6.97(270)$ & 130 & $5.17(200)$ \\
\hline \multicolumn{5}{|l|}{$\geq 5.69 \mathrm{mmol} / \mathrm{L}(220 \mathrm{mg} / \mathrm{dl})$ and/or drug use } \\
\hline No drugs & 491 & $6.34(245)$ & 491 & $6.34(245)$ \\
\hline$\geq 6.21 \mathrm{mmol} / \mathrm{L}(240 \mathrm{mg} / \mathrm{dl})$ & 25 & $7.05(273)$ & 40 & $6.70(259)$ \\
\hline $5.69-6.20 \mathrm{mmol} / \mathrm{L}(220-239 \mathrm{mg} / \mathrm{dl})$ & 23 & $6.97(270)$ & 34 & $5.96(230)$ \\
\hline$<5.69 \mathrm{mmol} / \mathrm{L}(220 \mathrm{mg} / \mathrm{dl})$ & 53 & $6.96(269)$ & 96 & $4.89(189)$ \\
\hline
\end{tabular}

*Adjusted for sex, 5-year age class, and case/control status by analysis of covariance; ‘cholesterol level prior to the medication was not available for some of the subjects; ${ }^{\ddagger}$ units of $\mathrm{mmol} / \mathrm{L}(\mathrm{mg} / \mathrm{dl})$.

both sexes and angina pectoris in men tended to be more frequent in the group with treated hypercholesterolemia. There was no significant difference in smoking, alcohol use, and physical activity among the 3 groups.

A significant increase in the risk of AMI was observed among those with untreated hypercholesterolemia compared with nonhypercholesterolemic subjects, regardless of the definition of hypercholesterolemia (Table 2). The adjusted OR of AMI for hypercholesterolemia with medication vs nonhypercholesterolemia was almost unity.

The risk of AMI among those with treated hypercholesterolemia, as compared with those having hypercholesterolemia without medication, was examined according to achieved levels of serum total cholesterol (Table 3). When the achieved levels were lower than the cutoff point, the risk of AMI was half as low as the risk for untreated hypercholesterolemia whichever of the 2 definitions of hypercholesterolemia was used. Those under medication who had serum total cholesterol levels equal to or greater than the cutoff point showed a lower risk of AMI than those not under medication, but the decrease was not statistically significant. In the analysis limited to individuals under treatment for hypercholesterolemia, adjusted ORs for attained cholesterol levels of $5.69-6.20 \mathrm{mmol} / \mathrm{L}(220-239 \mathrm{mg} / \mathrm{dl})$ and $<5.69 \mathrm{mmol} / \mathrm{L}(220 \mathrm{mg} / \mathrm{dl})$, as compared with $\geq 6.21 \mathrm{mmol} / \mathrm{L}$ $(240 \mathrm{mg} / \mathrm{dl})$, were 0.81 (95\% CI 0.26-2.53) and $0.68(0.26-$ $1.75)$, respectively.

Because those on hypolipidemic drugs were regarded as having hypercholesterolemia with no allowance for serum total cholesterol levels prior to medication, the achieved levels of serum total cholesterol may have been positively associated with the levels prior to medication. However, there was no indication that serum total cholesterol levels prior to medication correlated with the achieved levels among those under medication (Table4). Individuals with treated hypercholesterolemia had slightly higher levels of serum total cholesterol prior to medication than those with untreated hypercholesterolemia, but there was no significant variation in cholesterol levels before treatment among those under medication with different achieved levels of serum total cholesterol.

\section{Discussion}

The present study demonstrated that medication for hypercholesterolemia was associated with a substantial decrease in the risk of nonfatal AMI among hypercholesterolemic individuals in Japan. When the medication attained serum total cholesterol concentrations lower than the level of hypercholesterolemia, the risk of AMI was half that for untreated hypercholesterolemia. These findings indicate that medication for hypercholesterolemia also reduces the risk of AMI in Japanese subjects, although the observed size of the reduction in the risk associated with the medication needs to be interpreted with caution because of methodological limitations in the present study.

Selection and information bias are important issues that need careful consideration in case-control studies. Although a fairly large number of eligible cases participated in the study, participation of controls was not sufficiently good. If control subjects with hypercholesterolemia were more likely to participate in the study when they were under medication, the protective association between medication for hypercholesterolemia and the risk of AMI would be overestimated. However, it is unlikely that the participation of controls was differential as regards the current levels of serum total cholesterol among those with treated hypercholesterolemia. For both cases and controls, the use of lipid-lowering drugs was ascertained by referring to medical records or by inquiring directly of the primary physicians. It is known that serum total cholesterol concentrations begin to decrease on the second day of AMI ${ }^{24,25}$ so serum total cholesterol concentrations measured within $24 \mathrm{~h}$ of onset or alternatively prior to the onset are preferable. Approximately $25 \%$ of the cases had their serum total cholesterol concentration measured more than $24 \mathrm{~h}$ after onset and these delayed measurements probably resulted in values of serum total cholesterol slightly lower than the actual levels prior to the onset in some of the cases, and thus attenuated the association with attained levels of serum total cholesterol. The measurement of serum total cholesterol was done at different laboratories, but the measurements of most items in routine blood biochemistry, including total cholesterol, have been standardized among the clinical laboratories in Fukuoka Prefecture? 6

Another concern is that those with treated hypercholesterolemia may have had a greater chance of medical treatment for other conditions affecting the risk of AMI. Hypertension, defined as having ever used anti-hypertensive drugs, was more frequent among individuals with treated hypercholesterolemia than those with untreated hypercholesterolemia. Such improved medical care in the group of treated hypercholesterolemia may partly explain the decreased risk of AMI associated with medication for hypercholesterolemia. However, hypertension, diabetes mellitus, and angina pectoris were each associated with a 
significant increase in the risk of AMI (data not shown) when each of them was defined on the basis of medical treatment.

In primary prevention trials, the use of lipid-lowering drugs has consistently resulted in a substantial decrease in the occurrence of nonfatal MI as well as of overall CHD events among those with moderate or severe hypercholesterolemia. In the earliest trial comprising men with an average serum total cholesterol concentration of 6.44 $\mathrm{mmol} / \mathrm{L}(249 \mathrm{mg} / \mathrm{dl})$, a $9 \%$ decrease in total cholesterol by clofibrate was associated with a $25 \%$ reduction in the risk of nonfatal MI? In the Lipid Research Clinics Trial investigating men with a mean concentration of plasma total cholesterol of $7.54 \mathrm{mmol} / \mathrm{L}(291 \mathrm{mg} / \mathrm{dl})$, a $8.5 \%$ decrease in total cholesterol by cholestyramine resulted in a $19 \%$ reduction in nonfatal MI6 Further, a 10\% decrease in total cholesterol by gemfibrozil was reported by the Helsinki Heart Study ${ }^{7}$ and a $20 \%$ decrease by pravastatin by the West of Scotland trial ${ }^{8}$ and this resulted in $37 \%$ and $31 \%$ reduction, respectively, in the incidence of nonfatal MI among men with an average serum or plasma total cholesterol at baseline of approximately $7.0 \mathrm{mmol} / \mathrm{L}(270 \mathrm{mg} / \mathrm{dl})$. More recently, in men and women with an average serum total cholesterol level of $5.71 \mathrm{mmol} / \mathrm{L}(221 \mathrm{mg} / \mathrm{dl})$, a $18 \%$ decrease in total cholesterol by lovastatin resulted in a $40 \%$ reduction in the risk of fatal and nonfatal MI? Despite all these findings, it still remains unclear how aggressive the treatment for hypercholesterolemia should be?7

Although the present study indicated that lower levels of cholesterol were better at least in terms of reducing the risk of AMI, there was a wide variation in the achieved levels of serum total cholesterol among those under medication for hypercholesterolemia. Although statins were widely used (64\% of cases and $76 \%$ of controls), the treatment was not necessarily adequate because approximately $45 \%$ of those under medication had a serum total cholesterol level $\geq 5.69 \mathrm{mmol} / \mathrm{L}(220 \mathrm{mg} / \mathrm{dl})$; that is, the definition of hypercholesterolemia as used in Japan ${ }^{23}$ Further, it should be noted that many hypercholesterolemic subjects were untreated. Inadequate treatment for hypercholesterolemia is a matter of concern because hypercholesterolemia has become an important cause of CHD events in Japan! 18,28,29

A randomized controlled trial is a desirable design for investigating the efficacy of medical treatment for hypercholesterolemia in the prevention of CHD events, but is not feasible in populations with a low risk of CHD, and randomization may be affected by reluctance among medical professionals as well as patients in populations with different cultures, as was illustrated in a large-scale clinical trial of statin in Japan ${ }^{17,30}$ Under those circumstances, observational evidence would be of value when evidence from randomized trials is applied to a population with different characteristics. Well-designed observational studies are indeed a useful tool for examining whether the efficacy documented in a distinct group of patients under controlled conditions translates into effective treatment in routine clinical practice? 31,32

\section{Conclusions}

The present study had the methodological limitations of a case-control design, but showed a beneficial effect of medication for hypercholesterolemia in the primary prevention of CHD events in a Japanese population. It was also found that nearly half of those under medication for hypercholesterolemia still had relatively high levels of serum total cholesterol.

\section{Acknowledgments}

This study was financially supported by Sankyo, Co Ltd, Japan. Valuable support was provided by the Fukuoka City Medical Association, the Division of Internal Medicine of the Fukuoka City Medical Association, the Chikushi Medical Association, Itoshima Medical Association, Kasuya Medical Association and the Munakata Medical Association.

\section{References}

1. The Pooling Project Research Group. Relationship of blood pressure, serum cholesterol, smoking habit, relative weight and ECG abnormalities to major coronary events: Final report of the Pooling Project. $J$ Chron Dis 1978; 31: $201-206$.

2. Stamler J, Wentworth D, Neaton JD for the MRFIT Research Group. Is relationship between serum cholesterol and risk of premature death from coronary heart disease continuous or graded? Findings in 356,222 primary screenees of the Multiple Risk Factor Intervention Trial (MRFIT). JAMA 1986; 256: $2823-2828$.

3. Pocock SJ, Shaper AG, Phillips AN. Concentrations of high density lipoprotein cholesterol, triglycerides, and total cholesterol in ischemic heart disease. BMJ 1989; 298: $998-1002$.

4. LaRosa JC, Hunninghake D, Bush D, Criqui MH, Getz GS, Gotto AM, et al. The cholesterol facts: A summary of the evidence relating dietary fats, serum cholesterol, and coronary heart disease: A joint statement by the American Heart Association and the National Heart, Lung, and Blood Institute. Circulation 1990; 81: 1721-1733.

5. The Committee of Principal Investigators. A co-operative trial in the primary prevention of ischemic heart disease using clofibrate. $\mathrm{Br}$ Heart J 1978; 40: 1069-1118.

6. The Lipid Research Clinics Program. The Lipid Research Clinics Coronary Primary Prevention Trial results. I. Reduction in incidence of coronary heart disease. JAMA 1984; 251: 351-364.

7. Frick MH, Elo O, Haapa K, Heinonen OP, Heinsalmi P, Helo P, et al. Helsinki Heart Study: Primary-prevention trial with gemfibrozil in middle-aged men with dyslipidemia: Safety of treatment, changes in risk factors, and incidence of coronary heart disease. $N$ Engl J Med 1987; 317: $1237-1245$.

8. Shepherd J, Cobbe SM, Ford I, Isles CG, Lorimer AR, Macfarlane $\mathrm{PW}$, et al for the West of Scotland Coronary Prevention Study Group. Prevention of coronary heart disease with pravastatin in men with hypercholesterolemia. N Engl J Med 1995; 333: 1301-1307.

9. Downs JR, Clearfield M, Weis S, Whitney E, Shapiro DR, Beere PA, et al. Primary prevention of acute coronary events with lovastatin in men and women with average cholesterol levels: Results of AFCAPS/ TexCAPS. JAMA 1998; 279: 1615-1622.

10. Scandinavian Simvastatin Survival Study Group. Randomised trial of cholesterol lowering in 4444 patients with coronary heart disease: The Scandinavian Simvastatin Survival Study (4S). Lancet 1994; 344: $1383-1389$.

11. Byington RP, Jukema JW, Salonen JK, Pitt B, Bruschke AV, Hoen $\mathrm{H}$, et al. Reduction in cardiovascular events during pravastatin therapy: Pooled analysis of clinical events of the pravastatin atherosclerosis intervention program. Circulation 1995; 92: 2419-2425.

12. Sacks FM, Pfeffer MA, Moye LA, Rouleau JL, Rutherford JD, Cole TG, et al. The effect of pravastatin on coronary events after myocardial infarction in patients with average cholesterol levels. $N$ Engl J Med 1996; 335: $1001-1009$.

13. The Long-Term Intervention with Pravastatin in Ischaemic Disease (LIPID) Study Group. Prevention of cardiovascular events and death with pravastatin in patients with coronary heart disease and a broad range of initial cholesterol levels. N Engl J Med 1998; 339: 13491357.

14. Szatrowski TP, Peterson AV Jr, Shimizu Y, Prentice RL, Mason MW, Fukunaga Y, et al. Serum cholesterol, other risk factors, and cardiovascular disease in a Japanese cohort. J Chron Dis 1984; 37: 569-584.

15. Chen Z, Peto R, Collins R, MacMahon S, Lu J, Li W. Serum cholesterol concentration and coronary heart disease in population with low cholesterol concentrations. BMJ 1991; 303: 276-282.

16. Tamura A, Mikuriya Y, Nasu M. Effect of pravastatin $(10 \mathrm{mg} /$ day) on progression of coronary atherosclerosis in patients with serum total cholesterol levels from 160 to $220 \mathrm{mg} / \mathrm{dl}$ and angiographically documented coronary artery disease: Coronary Artery Regression Study (CARS) Group. Am J Cardiol 1997; 79: 893-896.

17. The Kyushu Lipid Intervention Study Group. A coronary primary 
intervention study of Japanese men: Study design, implementation and baseline data. J Atheroscler Thromb 1996; 3: 95-104.

18. Miyake Y, Fukuoka Heart Study Group. Risk factors for non-fatal acute myocaridal infarction in middle-aged and older Japanese. Jpn Circ J 2000; 64: 103-109.

19. Sasazuki S, the Fukuoka Heart Study Group. Case-control study of nonfatal myocardial infarction in relation to selected foods in Japanese men and women. Jpn Circ J 2001; 65: 200-206.

20. The Lipid Research Clinics Program. The Coronary Primary Prevention Trial: Design and implementation. J Chron Dis 1979; 32: 609-631.

21. Ainsworth BE, Haskell WL, Leon AS, Jacobs DR Jr, Montoye HJ, Sallis JF, et al. Compendium of physical activities: Classification of energy costs of human physical activities. Med Sci Sports Exerc 1993; 25: 71-80.

22. Expert Panel on Detection, Evaluation, and Treatment of High Blood Cholesterol in Adults. Executive summary of the third report of the National Cholesterol Education Program (NCEP) Expert Panel on Detection, Evaluation, and Treatment of High Blood Cholesterol in Adults (Adult Treatment Panel III). JAMA 2001; 285: 2486-2497.

23. The Japanese Atherosclerosis Society. Conference consensus. J Jpn Atheroscler Soc 1987; 15: 1109-1148 (in Japanese).

24. Gore JM, Goldberg RJ, Matsumoto AS, Castelli WP, McNamara PM, Dalen JE. Validity of serum total cholesterol level obtained within 24 hours of acute myocardial infarction. Am J Cardiol 1984; 54: 722 725 .

25. Sasaki J, Kawano T, Sasaki Y, Ishihara Y, Sata T, Arakawa K. Serum lipid and apolipoprotein profiles after onset of acute myocardial infarction. Jpn Circ J 1984; 48: 546-551.

26. Hamasaki N, Kinoshita S. Harmonization of laboratory data and establishment of reference intervals in Fukuoka Prefecture. Igakuno-ayumi 1998; 184: 659-663 (in Japanese).

27. Kastelein JJP. The future of best practice. Atherosclerosis 1999; 143(Suppl 1): S17-S21

28. Washio M, Sasazuki S, Kodama H, Yoshimasu K, Liu Y, Tanaka K, et al. Role of hypertension, dyslipidemia and diabetes mellitus in the development of coronary atherosclerosis in Japan. Jpn Circ J 2001; 65: $731-737$

29. Nakamura T, Tsubono $Y$, Kameda-Takemura K, Funahashi T, Yamashita S, Hisamichi S, et al. Magnitude of sustained multiple risk factors for ischemic heart disease in Japanese employees: A casecontrol study. Jpn Circ J 2001; 65: 11-17.

30. The Kyushu Lipid Intervention Study Group. Pravastatin use and risk of coronary events and cerebral infarction in Japanese men with moderate hypercholesterolemia: The Kyushu Lipid Intervention Study. J Atheroscler Thromb 2000; 7: 110-121.

31. Concato J, Sham N, Horwitz RI. Randomized, controlled trials, observational studies, and the hierarchy of research designs. $N$ Engl J
Med 2000; 342: 1887-1892.

32. Pocock SJ, Elbourne DR. Randomized trials or observational tribulations? N Engl J Med 2000; 342: 1907-1909.

\section{Appendix}

The members of the Fukuoka Heart Study Group are listed in alphabetical order for each affiliation. *Principal Investigator, ${ }^{\dagger}$ Co-principal Investigator.

Hiroko Kodama, Suminori Kono* Ying Liu, Shizuka Sasazuki, Keitaro Tanaka, Shoji Tokunaga, Kouichi Yoshimasu, Masakazu Washio (Department of Preventive Medicine, Graduate School of Medical Sciences, Kyushu University; these are also the members of the working group); Masahiro Mohri, Akira Takeshita (Department of Cardiovascular Medicine, Graduate School of Medical Sciences, Kyushu University); Kikuo Arakawa, Munehito Ideishił Takanobu Nii, Kazuyuki Shirai (Second Department of Internal Medicine, School of Medicine, Fukuoka University); Koichi Handa, Keiichi Tanaka (Department of Emergency and Critical Care Medicine, School of Medicine, Fukuoka Univeristy); Hidekazu Arai (Tokushukai Fukuoka Hospital); Yoshitaka Doi, Tomoki Kawano, Osamu Nakagaki, Kazuyuki Takada (Saiseikai Fukuoka General Hospital); Yasushi Sasaki (Ishihara Cardiovascular Disease Hospital); Yasushi Ishihara (Odo Ishihara Hospital); Tetsuji Inoh (Fukuoka Red Cross Hospital); Fumio Oshima (Fukuoka Medical Association Hospital); Tomoki Honma, Samon Koyanagi (National Kyushu Medical Center Hospital); Yasuo Hayashi, Yuji Taira (Hara Sanshin General Hospital); Yuji Maruoka (Hamanomachi Hospital); Ken Abe (Chihaya Hospital); Shunji Miake, Suguru Mori, Shinya Oda (Hakujuji Hospital); Ryuichi Nagashima, Ichiro Ohmura (National Sanatorium Fukuokahigashi Hospital); Tadayuki Hiroki, Ryuichiro Miyawaki (Fukuoka University Chikushi Hospital); Juzabu Jinnouchi (Sasaguri Hospital); Shinichiro Ito, Kazuyuki Saito (Fukuoka Seishukai Hospital); Terutoshi Tanioka (Munakata Suikokai Hospital); Kohzo Iino (Itoshima Medical Association Hospital); Yasuhiro Maeda (Munakata Medical Association Hospital); Yasuhiko Orita (Fukuoka Kameyama-eikoh Hospital); Yohsuke Katsuta, Hidero Nakazono (Saiseikai Futsukaichi Hospital); Naotaka Hamasaki (Department of Clinical Chemistry and Laboratory Medicine, Graduate School of Medical Sciences, Kyushu University); Hitomi Hayabuchi (Fukuoka Womens' University); Sumie Jingu, Ryoko Hayashi, Masako Sakamoto (Fukuoka City Office); Yoshiki Egashira, Tadashi Enomoto, Masanori Fujino, Keisuke Fukuda, Masakazu Gondo, Shouhei Hata, Satoshi Hiratsuka, Takashi Ichiki, Nariaki Ikeda, Yasuto Iwanaga, Hisashi Kanaya, Yoshihiro Kato, Masaki Kohara, Nobuo Masuda, Hideyo Matsuguchi, Eiichi Murayama, Masatsugu Ohga, Hideaki Ogushi, Nobuo Ouchi, Hiroshi Saku, Teizo Sata, Kuninori Soejima, Hiroshi Takamiya, Shinsuke Takei, Masafumi Tanaka, Noritami Tashiro, Takehiko Yamada, Tsutomu Yamamoto, Masato Yoshida (General Practioners in Fukuoka City). 